\title{
CHAPTEK 128
}

HEAD LOSS AT TSUNAMI-BREAKWATER OPENING

by Yoshryukı ITO*

\begin{abstract}
The head loss at breakwater openung 18 inportant factor for evaluating the effect of breakwaters aganst tsunam. This paper examines the coefficient of the head loss term in the equation of motion by comparang the results of numerical calculations wath the actual record observed an the port of of unato at the time of 1968 tsunami. Numerical calculations are repeated changing the head loss coefficlent from zero to 3.0 whth the interval of 0.5 . The calculated water level variation is quite different from the record if no head loss is taken into consideratzon. Although the most suztable value of the coefficlent is not definitely determined, the value of 1.5, which has been adopted in our previous calculations, seems to be reasonable for practical purpose.
\end{abstract}

\section{Introduction}

The construction of tsunami-breakwaters in the Port of of unato and several other harbours was started after the dzsaster due to Chilean Earthquake Tsunami in 1960. Concerning this project the author studied the effect of breakwaters against tsunam mainly by numerical calculations The method of calculation and some results obtalned were reported to 10th Coastal Engineering Conference held in Tokyo in 1966 (Reference 1).

In May 1968, the tsunam-breakwater in the Port of ofunato experienced the first remarkable tsunam since its completion in 1967. The water level variation was recorded by two tide gauges located outside and inside the breakwater. The author immediately applied the method of calculation and obtained a good agreement between calculation and observation. The effect of the tsunami-breakwater was also confirmed by this onalysis. The detalls were already reported to 13th IAHR Congress in Kyoto, 1969 (Reference 2).

The term of head loss included in the equation of motion at the breakwater opening plays an important role in numerical calculation. If no head loss is taken into account, the effect of breakwaters against tsunam is not appropriately evaluated due to the appearance of so-called harbor-paradox. The author has so far adoted the head loss coefficlent of 1.5 in previous calculations. The influence of thrs coefficient on the calculated results is examned in this paper by comparing the calculations with the actual observation of 1968 tsunami in the Port of ofunato.

* Hydraulics Division, Port and Harbour Research Institute, Ministry of Transport 3-1-1, Nagase, Yokosuka, Japan 


\section{Basic Equations}

The principle of calculation $2 \mathrm{~s}$ to solve numerically the equations of motion and of continulty for two-dimensional long wave under certain initial and boundary conditions. Fundamental equations are as follows,

$$
\begin{aligned}
& \frac{\partial u}{\partial t}=-g \frac{\partial \zeta}{\partial x} \\
& \frac{\partial v}{\partial t}=-g \frac{\partial \zeta}{\partial y} \\
& \frac{\partial \zeta}{\partial t}=-\frac{\partial}{\partial x}(h u)-\frac{\partial}{\partial y}(h v)
\end{aligned}
$$

where, $u, v=v e l o c i t y$ component in $x$ - and $y$-direction, respectively $\zeta=w a t e r$ level elevation with respect to mean water level $h=$ water depth below mean water level

These differential equations are transformed into difference equations. Figure 1 shows the grid system around the breakwater in the Port of ofunato. The grid interval in this case is 280 metres and the time interval is 10 seconds.

The outer sea $2 \mathrm{~s}$ replaced by a channel of constant depth and wadth, where the computation is only almed at supplying the incoming tsunam whthout being affected by reflected waves from the breakwater and shorelines. As a boundary condztzon, velocity components normal to the breakwater and shorelines are gaven to be zero. The calculation 25 started from the time when the front of tsunami arrives at the bey-nouth. Inztial water level and velocity inside the bay are accordingly zero, whle those in the outer sea correspond to the incldent tsunami profile.
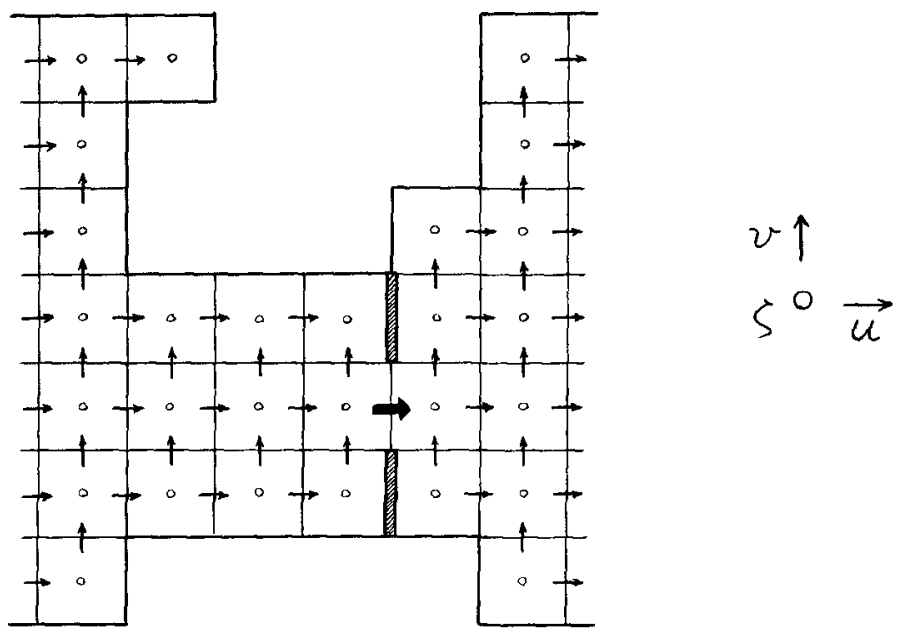

Figure 1 Grid System for Numerical Calculation 
Al though higher order terms for inertia or bottom friction are neglected in Equation (1), a term representing the head loss is added to the equation of motion at the breakwater opening as shown in the following difference equation,

$$
\frac{\Delta_{t} u}{\Delta t}=-g \frac{\Delta_{x} \zeta}{\Delta x}-\frac{f}{2 \Delta x}-u|u|
$$

The head loss coefficient $f$ in this equation has been assumed to be 1.5 in previous calculations. In this paper numerical calculations are carried out with $f$ of $0,05,1.0, \ldots, 3.0$.

1968 tsunams in the Port of of unato

Figure 2 shows the plan of Of unato Bay situated in the northeastern part of Japan along the Paclfic Coast. The tsunamibreakwater near the bay-mouth, where the maximum water depth reaches almost 40 metres, was constructed after ChIlean Earthquake Tsunami in 1960 and was completed in 1967.

on May 16, 1968, an earthquake of magnitude 7.8 occurred of $f$ this district A tsunami accompanied by this earthquake attacked the coast and caused certain damages to several ports. The tsunampbreakwater in the Port of Ofunato effectively protected the harbour and the city by reducing the water level elevation in the inner basin.

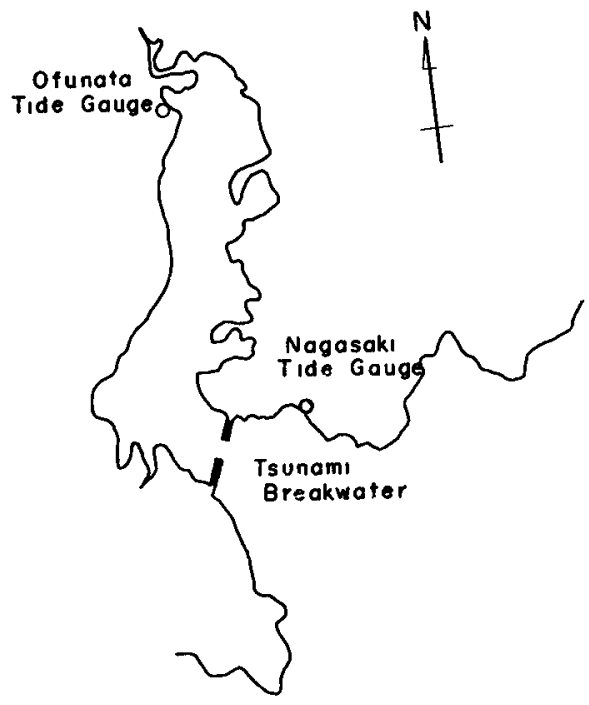

F1gure 2 Tsunam-breakwater and Tide Gauges in the port of of unato 
Actual records of water level variation were obtalned at two tide gauges, the one is located between the bay-mouth and the breakwater (Nagasakz) and the other is at the innermost part of the bay (Ofunato). The position of these tide gauges is indicated in Figure 2.

Figure 3 shows the water level variations during the first two hours, the astronomacal tide being subtracted.

In the analysis of this tsunamz by applying the author's method, the incident tsunami profile for calculation was determined so that the calculated water level variation at the outside tide gauge might be as close as possible to the observation. The outline of the procedure for this determination is as the following,

1) The water level variation at the outside tide gauge during the first 124 minutes, in which most of the major fluctuations are included, 28 analyzed into Fourier sine series.

2) Calculations are repeated for component regular sinusozdal waves in order to obtain the amplifyung factor at the outside tide gauge. The amplifyzng factor obtazned varies from 1.7 to 2.9.

3) The amplitude of each component obtalned in the Item 1) is divided by the corresponding amplifying factor in the item 2 ). The Fourier sine series consisting of thus determined amplitudes gives the approximate profile of the incident tsunam.

With this incident tsunam profile, a good agreement was confirmed between the calculation and the observation at the inside tide gauge. A calculation with the same incident tsunami was also carried out for the harbour before the construction of the tsunamibreakwater. The highest water level elevation in the harbour after the breakwater construction is 1.1 1.2 metres, whle without the breakwater It reaches more than 2 metres. The effect of the tsunamibreakwater 18 definitely evaluated by these numerical calculations

\section{Influence of the head loss coefficzent on calculated results}

The incident tsunami profile determined by the above-mentioned procedure will be affected to a certain extent by the head loss coefficient at the breakwater opening. However, the profile for $f=1.5$ is commonly used $2 n$ this paper to all the cases from $f=0$ to 3.0. The influence of the value of $f$ on the water level at the outside tide gauge is comparatively small, as shown in Figure 4.

Figure 5 is the comparison between calculation and observation at the inside tide gauge. This figure indicates that the curve for $f=0$ is quite different from the actual record, not only in the value at each peak or trough but also in the form of the curve itself.

Table 1 shows the computed and observed water level elevations at several peaks and troughs. The value of $f$ fitted to the observation differs at each position, as indicated by the mark (*) in the colum of calculation.

Figure 6 shows the goodness of fit of computed water level. The goodness is measured by the root mean square $(\sigma)$ of the residuals at every two minutes during two hours $(N=60)$.

$$
\sigma=\sqrt{\sum\left(\zeta_{\text {cal }}-\zeta_{\text {obs }}\right)^{2} / N}
$$




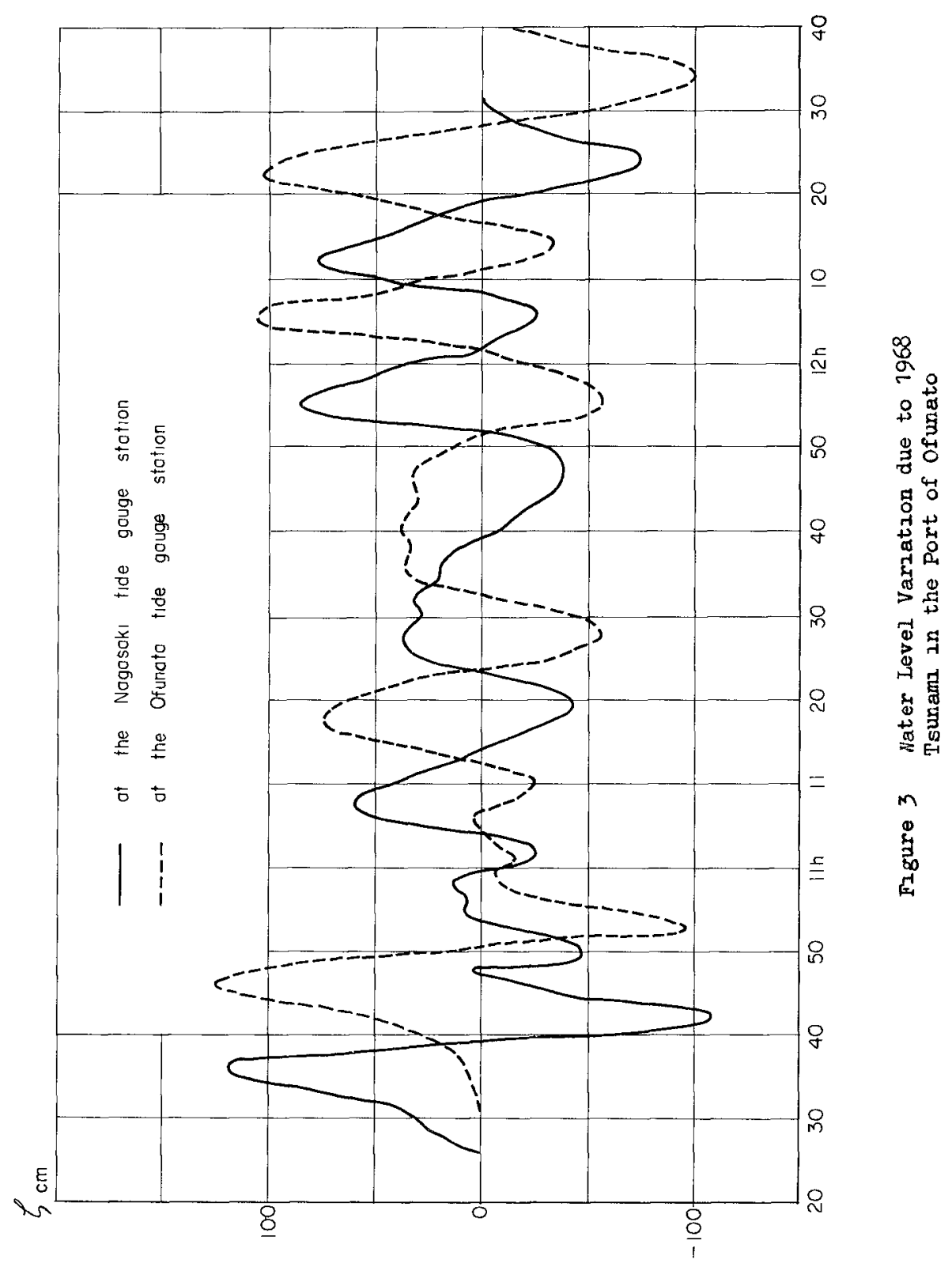




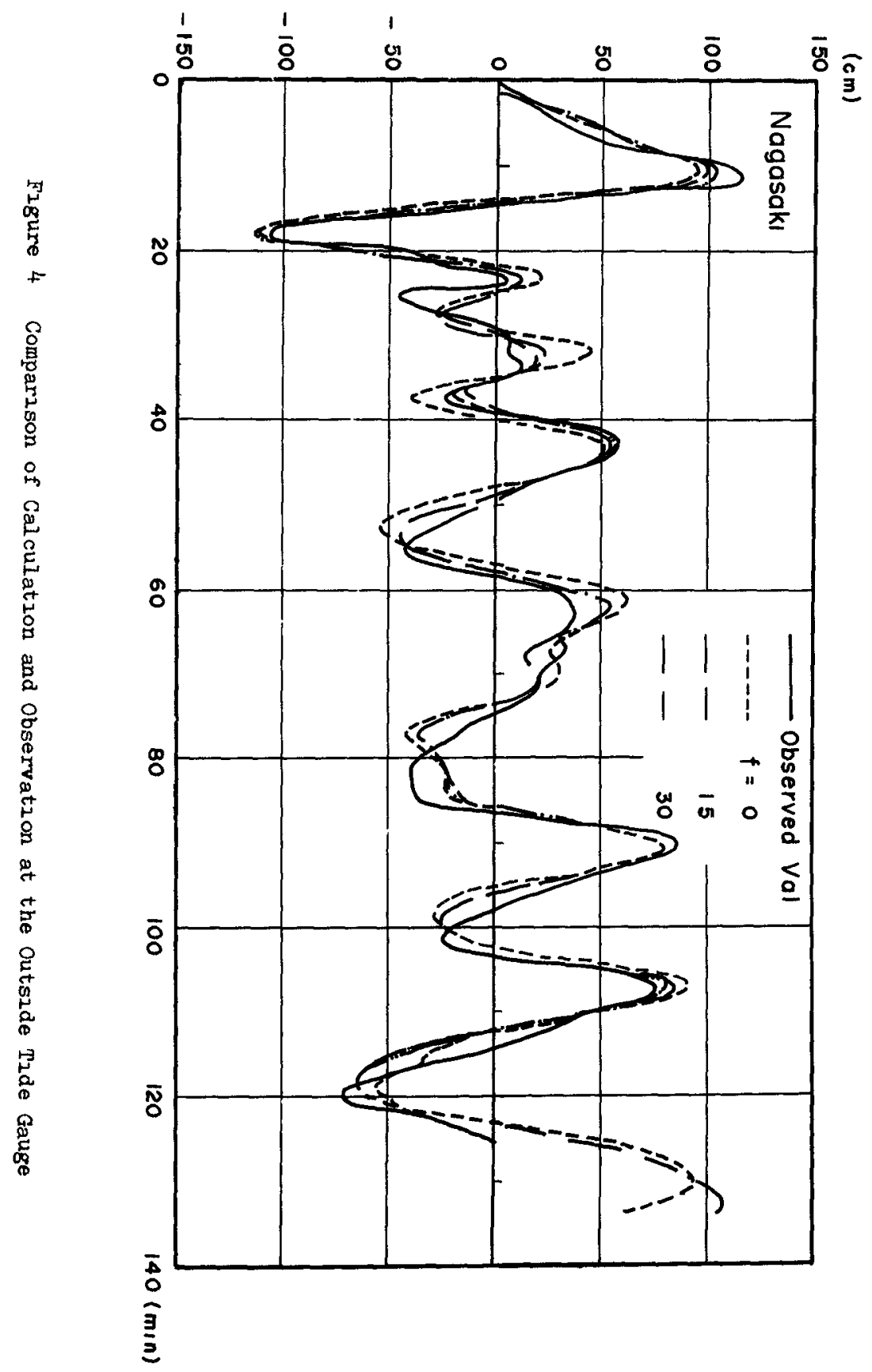




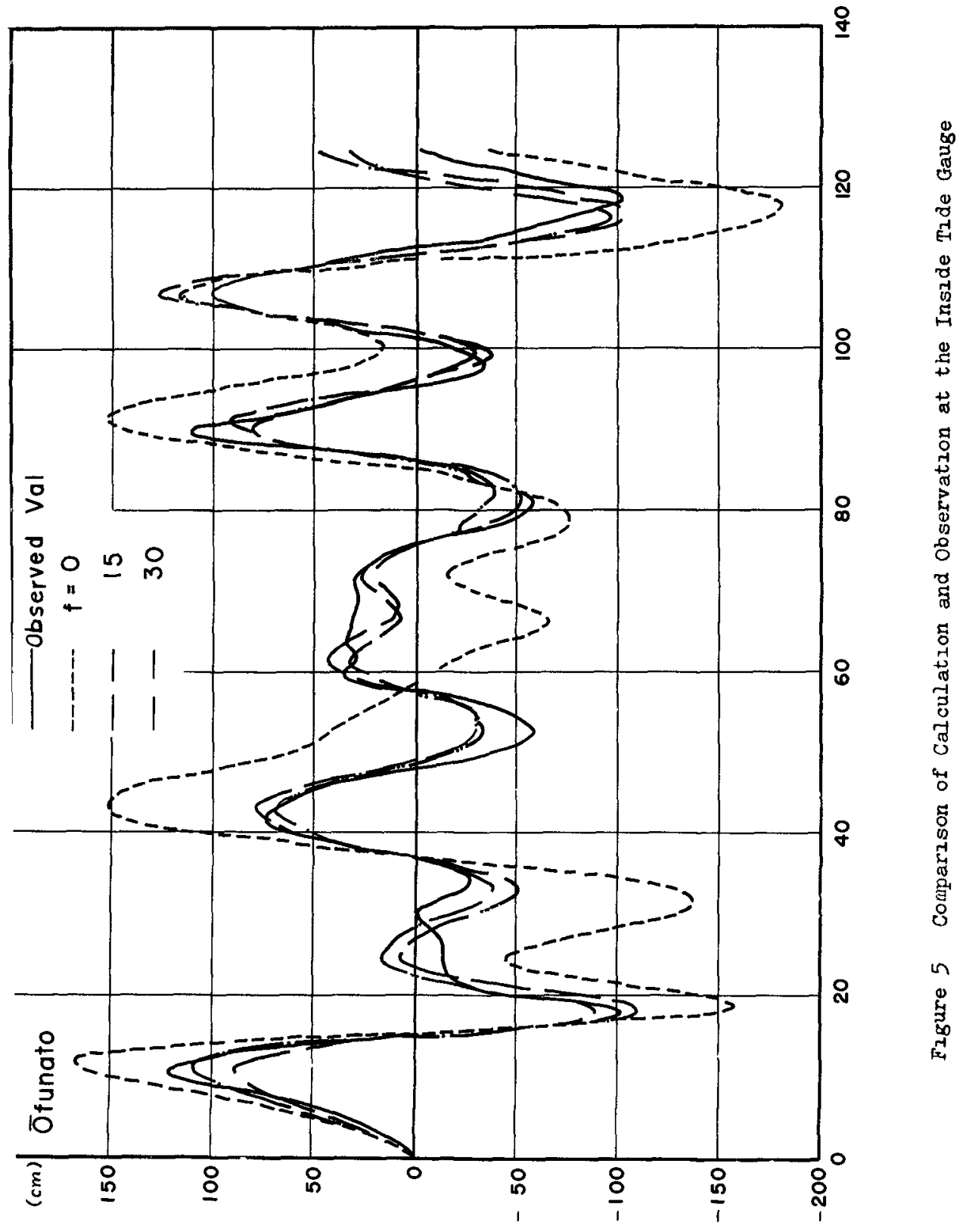


Table 1 Comparison of Calculation and Observation at Peaks and Troughs

(unzt $\mathrm{cm}$ )

\begin{tabular}{l|r|rrrrrrr}
\hline \multirow{2}{*}{ Position } & \multirow{2}{*}{ Observatzon } & \multicolumn{7}{|c}{ Calculation } \\
\cline { 3 - 8 } & & $f=0$ & 0.5 & 1.0 & 1.5 & 2.0 & 25 & 3.0 \\
\hline 1st peak & 124 & 169 & 140 & $123^{*}$ & 111 & 103 & 96 & 91 \\
1st trough & -102 & -159 & -137 & -120 & -108 & $-101 *$ & -95 & -90 \\
3rd peak & 74 & 153 & 104 & 88 & 80 & $75^{*}$ & 72 & 69 \\
4th peak & 112 & 153 & $108 *$ & 100 & 94 & 90 & 85 & 81 \\
6th peak & 102 & 119 & 138 & 134 & 129 & 123 & 119 & $115^{*}$ \\
6th trough & -101 & -180 & -121 & -111 & -105 & $-102^{*}$ & -99 & -97 \\
\hline
\end{tabular}

Al though the incident tsunam profile has been determined so that the computed water level at the outside tide gauge might colneide with the observed record, there still remain some differences between calculation and observation. The deviation of calculation for the anside tide gauge wil I depend on both the accuracy of the incident tsunam profile and the value of the head loss coefficient $f$.

At the inside tide gauge, the root mean square of the residuals is very bis at $f=0$. It decreases rapidly with the increase of $f$ and becomes almost constant for $f$ of bigger than 1.0 .

It is not easy to find out definitely the most suitable value of $f$ from these results. However, the analysis in this paper suggests the practical validity of the adoption of 1.5 or so as the head loss coefficlent at the tsunami-breakwater openzng, as far as the form of the equation of motion in our method of calculation is concerned.

References

1) H. Fukuuch2, Y. Ito on the Effect of Breakwaters against Tsunamı, Proc. 10th Conference on Coastal Englneering (Tokyo, 1966), pp.821 839

2) Y. Ito on the Ef fect of ofunato Tsunam-Breakwater against 1968 Tsunaml, Proc. 13th Congress of IAHR (Kyoto, 1969), Vol.3, pp.85 -93 


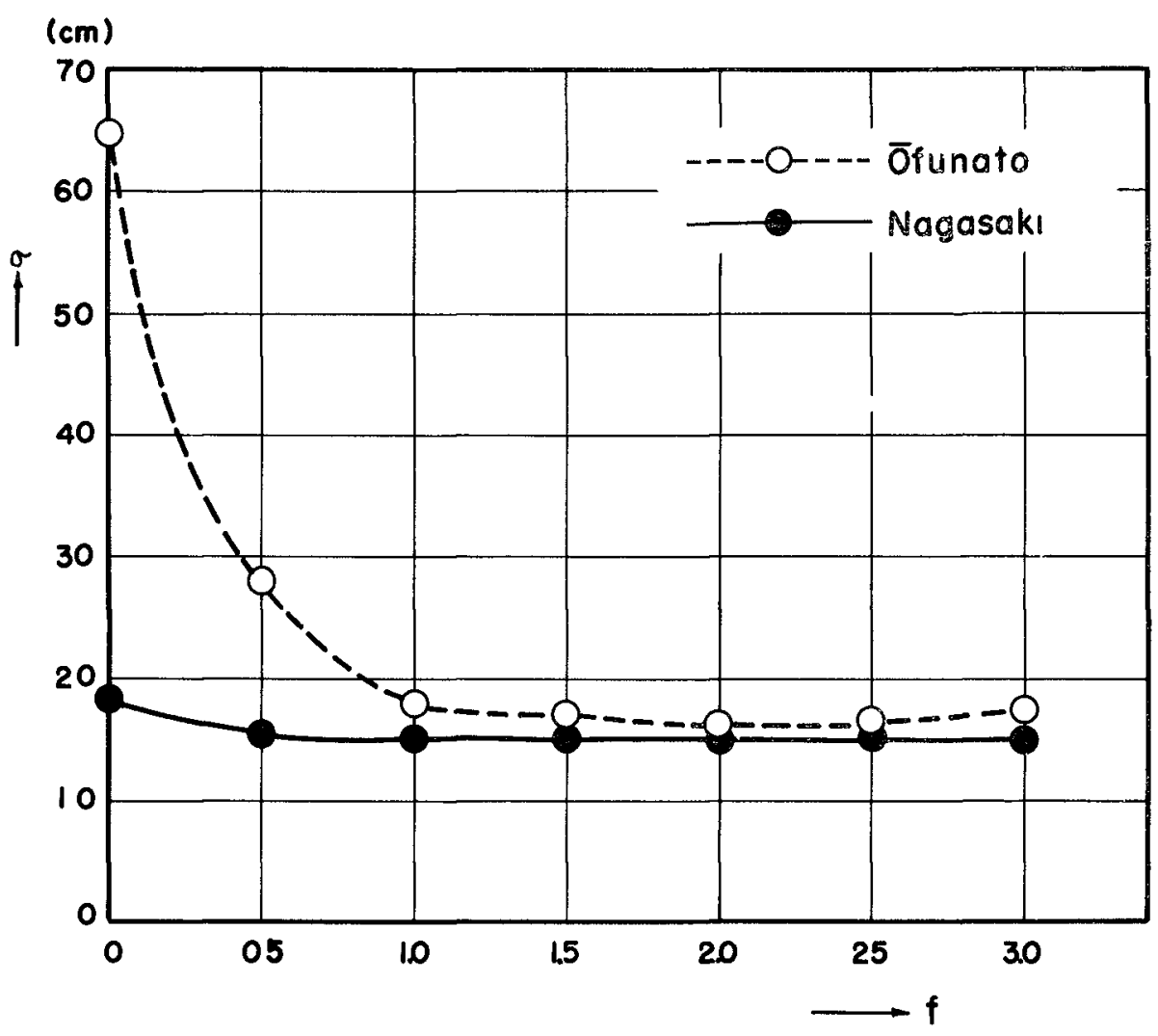

Figure 6 Goodness of Fit 
